\title{
Original Article \\ Assessment of Storage and Inventory Practices to Improve Medicine Supply Chain in Jubek State South Sudan
}

\author{
Adut Jervase Manyuat ${ }^{*}$, Kashi Carasso ${ }^{1}$, Mulatedzi Makhado ${ }^{1}$ \\ ${ }^{1}$ EAC Regional Centre of Excellence for Vaccines, Immunization, and Health Supply Chain \\ Management, College of Medicine and Health Sciences, University of Rwanda, Kigali, Rwanda.
}

*Corresponding Author: Adut Jervase Manyuat. EAC Regional Centre of Excellence for Vaccines, Immunization, and Health Supply Chain Management, College of Medicine and Health Sciences, University of Rwanda, Kigali, Rwanda. Email:gjervase@gmail.com

\section{Abstract}

\section{Background}

In order to deliver quality health services, safe, effective, affordable and quality medicines are needed. Inappropriate storage conditions, poor infrastructure and poor medicine management practices may lead to poor medicines quality, stock damage and expiration.

\section{Objective}

Assess storage and inventory practices to improve the medicine supply chain in South Sudan.

\section{Methodology}

The study used a descriptive cross-sectional design. The study population comprised 12 Health Centers in Juba where inventory management was practiced. Both questionnaire-guided interviews for staff self-assessment, and observer assessment were used by the researcher. With regard to storage and inventory management, the researcher collected data on the condition of storerooms with regards to availability of enough storage space, availability of enough storage equipment, and temperature conditions of the medicines stores, among others.

\section{Results}

The study found that store and inventory management practices varied widely in the different health facilities. Hospitals and central medical stores exhibited good or average inventory and storeroom management practices, respectively. The two hospitals and medical stores scored $100 \%$ in the elements in the assessment of storerooms and stock management. Some primary health care centers exhibited good inventory and store room management practice, whilst others were rated as average or poor. Most of the elements assessed scored 37\% in storeroom assessment while elements assessed for inventory management scored less than $75 \%$. There was great similarity between the observation assessment and the self-assessment.

\section{Conclusion}

In conclusion, store and inventory management practices and knowledge of the respondents varied in the different health facilities. Hospitals and central medical stores exhibited good, average and poor inventory and storeroom management practices assessed through self-assessment and observation assessment by the researcher. There was a great similarity between the observation assessment and the self-assessment Rwanda J Med Health Sci 2021;4(2): 310-320

Keywords: inventory, inventory management, medicine storage, medicine supply chain. 


\section{Background}

A third of the world population cannot access essential medicines, which are vital for the delivery of quality health services.[1] Medicines are required to be safe, effective, affordable, adequate, and available at the right time and in appropriate doses. [2] The reasons contributing to medicine deficiency include poor management practices and unsuitable storage conditions for medicines, given that their quality is affected by light, humidity, ventilation, temperature, sanitation conditions, as well as poor storage infrastructure.[2] As a result, medicine stock damage, expiration and theft are common occurrences.[2]

In medical supply systems, storage of medicines involves keeping medicines safe and without damage at any point in the medicine supply cycle.[3,4] In case medicines are damaged or stolen, shortages or stock outs may occur in the health facilities since damaged medicines would not be suitable for use.[5]

Storage of medicines in the warehouse generally needs appropriate security and temperature conditions in the storage area. Better inventory management practice is important in ensuring adequate stock levels, and it involves practices such as regular inventory taking, reconciliation of inventory, dispatching of medicines according to expiry and tracing of the batch numbers.[5] Medicine storage is one of the most important responsibilities that can be best handled by a pharmacist.[6] The two most important factors that affect the quality of stored medicine usually takes place during medicine transit, because this activity often exposes the stock to temperature and humidity changes if precautions are not taken.[6]

After South Sudan seceded from Sudan, the country had insufficient health care facilities, poor medicines storage conditions and poor medicines management in various facilities across the country which adversely affected the quality of health services in Juba City. According to the South Sudan Health Sector Development Plan 20122016, it has been approximated that only $10 \%$ of the staffing norms were filled by appropriately trained health workers.[7] This makes proper storage of pharmaceuticals to be questionable.

According to South Sudan's National Adaptation Programme of Action (NAPA) to climate change, it is also noted that throughout the year, temperatures are extremely high in Jubek state which affects medicine storage due to high humidity, exposure to light and poor ventilation.[8]

To our best knowledge, there has been no research conducted to assess the storage conditions and inventory management in South Sudan. Therefore, the main objective of this research was to assess the storage conditions and inventory management practices for the medicines and its impact on medicines supply chain in South Sudan (Juba). Specifically, the study aimed to (1) assess medicine storerooms and inventory management practices in selected 
health facilities in Juba and (2) assess the knowledge of the health workers working in the store and inventory management.

\section{Methods}

\section{Study design}

A descriptive survey was applied in assessing the medicine storerooms and inventory management practices in selected health facilities in Juba. The researcher used both questionnaire-guided interviews for staff self-assessment, and observer assessment for data collection.

\section{Study population and sampling}

The study targeted all the 19 government health facilities including 2 government medical storage facilities in Juba City. Purposive sampling method was used to select 12 facilities which had medical stores. As a result, 2 hospitals, 2 medical stores and 8 primary health care centers with stores and inventory management practices were purposively sampled. The next step involved selecting from each government health facility or medical storage facility one store. The two hospitals selected were Juba teaching hospital and Al Sabbah Children's hospital. The two medical stores selected were central medical store and Jubek medical store. All the facilities were selected from Juba because Juba City has most of the health facilities serving a diverse population from the different ethnic groups and nationalities. The study focused on major health facilities with semi-autonomous storage and inventory management system. The targeted health centers were drawn from the Ministry of Health list for the purpose of sampling. The 12 selected medical stores were assessed using specific questionnaires regarding store and inventory management practices at health facilities. In addition, 4 store keepers and 1 pharmacist were interviewed using interview guide for their knowledge and capacity in inventory practice and management. The reason for selecting the 4 store keepers and 1 pharmacist out of the 12 facilities assessed is that the 5 facilities were the larger only ones that had staff with proper qualification and experience. The remaining facilities were Primary Health Care Units (PHCUs) and had a trained nurse or any health worker to run the functional medicine store and inventory system.

\section{Data collection instruments}

Questionnaires, observation checklist and interview guide were the tools used to collect the data.

\section{Questionnaire}

The questionnaire was used to collect data by filling the answers out after the researcher reading out the questions to the respondents. The questionnaire comprised of two sections, namely section "A" which had questions about assessments of storerooms and section $\mathrm{B}$ which assessed inventory practices of the selected health centers and hospitals. In assessing storage conditions in the storerooms, the researcher targeted points included availability of enough storage space, availability of enough storage equipment, and temperature conditions of the medicines store. Further information on stock management collected included how often medicines stock is taken, stock dispatch system being used and stock keeping documentation. Data were collected on expired drugs management, especially on the availability of expiry drugs recording system as well as the procedures for disposing expired drugs. 


\section{Interview guide}

An interview guide was used to collect information on knowledge of inventory management in CMS, Malakia PHCU, Juba teaching hospital and Al Sabbah children's hospital stores.

\section{Observation}

The researcher also used observation to assess the inventory and store management practices in the facilities. The researcher used an observation guide to see the storage conditions of medicines in the stores assessed and then ticked the observation guide based on what was observed. The guide used 20 points for observation including classification of medicines in the shelves by dosage or therapeutic form, presence of expiry medicines in the shelves, arrangement of medicines according to expiry, separation of expired medicines from unexpired, and availability of stock cards in the stores.

\section{Measurements}

The study measured quality of the services as dependent variable against the storage conditions and inventory management practices as independent variables.

\section{Data collection Procedure}

The researcher obtained an authorization letter from the Ministry of Health South Sudan. An authorization letter was presented to the administration of each health facilities and hospital to enable the researcher to interview the targeted respondents to collect the required data for purpose of the study. The researcher then approached the purposively selected respondents. The researcher read the questionnaires to the respondents to answer the questions relevant to the research and then ticked the answers. Equally for the interview, the researcher asked the questions and wrote down the answers given by the respondents.

\section{Data Analysis}

Data collected using questionnaire was cleaned and entered into SPSS version 20. Descriptive statistics were mainly used. In addition, narrative analysis was used to present the qualitative results.

\section{Ethical consideration}

The information that the respondents provided was treated confidentially and was used only to serve academic purpose. The researcher ensured that the anonymity and confidentiality of the respondents was maintained. This was through ensuring that the name of the health facility and respondents did not appear in the questionnaire. An official authorization was sought by the researcher from ministry of health South Sudan to carry out data collection in the targeted hospitals and health facilities. The researcher ensured that the administration of each hospital and health facilities was approached before any data collection started. An overall approval was granted from ministry of health South Sudan, but also each of the 12 health facilities assessed granted permission before data was collected. 


\section{Results}

\section{Storeroom management conditions for the two hospitals assessed}

In the two hospitals visited, two people were assessed using the assessment questionnaires. The hospitals were found to have excellent storeroom management. In the two hospitals, the results indicated that: (1) drug products were protected from sunlight, (2) products were stored in a systematic way (in alphabetical order, systematic), (3) windows had curtains and are secured with grills, (4) store ceiling was in good condition without any dampness, (5) the proper fire prevention and extinguishing equipment were present, (6) store was kept locked at all times when not in use, (7) there were doors with adequate locks and keys, (8) there was proper lighting in the store room for the medicines all the time, (9) store room for medicines was well ventilated, (10) dispensing was not done from the main warehouse, (11)store was free of pests (i.e. cockroaches, rats, mice) with no sign of infestations, and (12) store was tidy, shelves were not dusted, floor was swept and walls were clean. Also the inventory management practices in the hospitals were according to the ABCs of medicine in most of the assessment questions checked. Expired medicines management was found to be good in the two hospitals assessed as shown in figure 1 below.

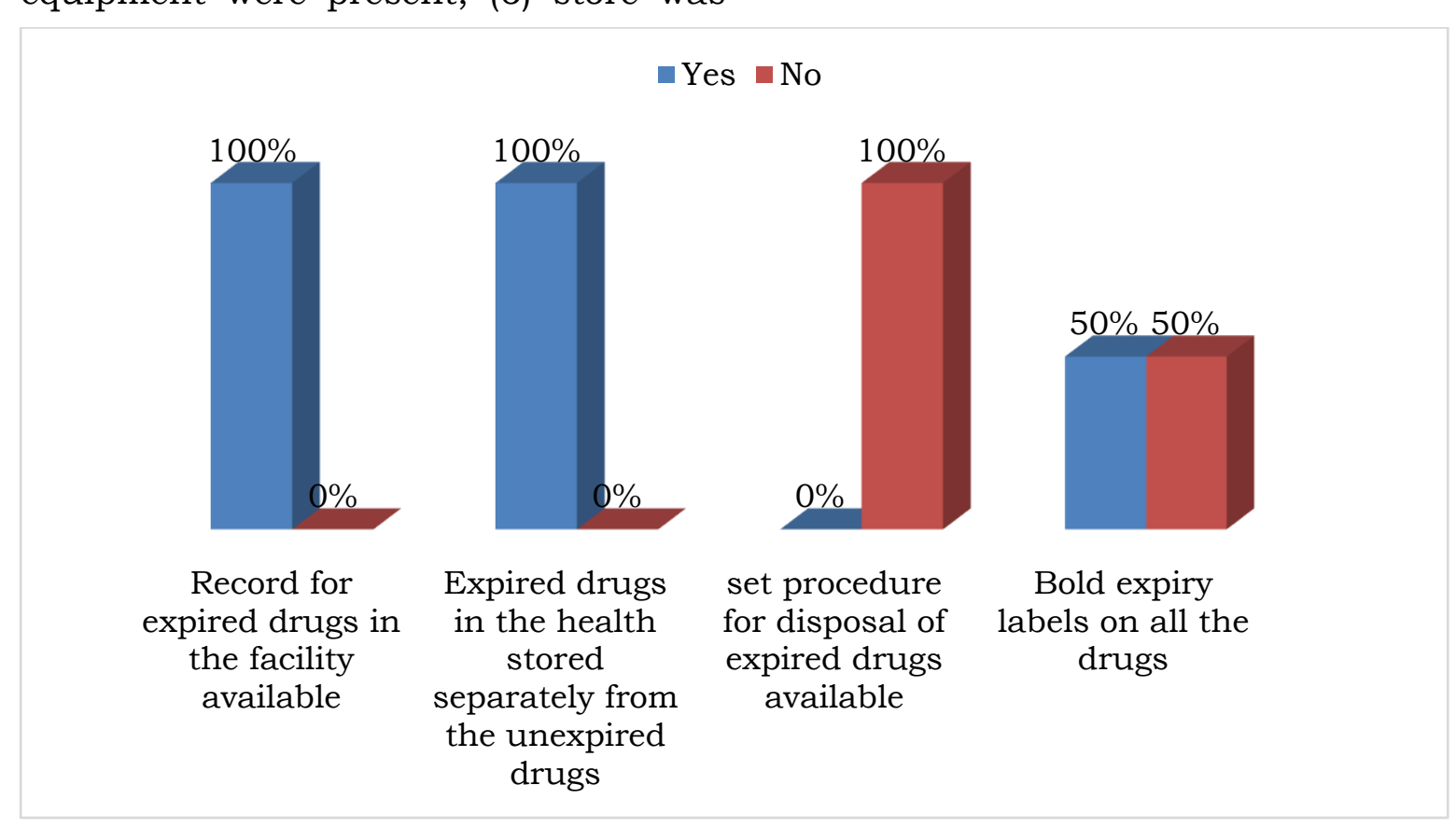

\section{Figure 1. Results showing expiry drugs management practices in the hospitals assessed}

\section{Storeroom management conditions of the two medical stores assessed}

In the two central medical stores assessed, storeroom condition was found to be good. The inventory management practice of the two medical stores assessed were found to be excellent as most of the items met the requirements for medical store. These items were: (1) pharmacist is responsible for stocking and receiving medicines, (2) stock cards exist for each item in the store, (3) stock card kept on the same shelf as the item, (4) drugs requisition by various departments are recorded, traceability of batches is assured, (6) 
they use bin card for stock keeping forms to manage health products in the facilities, (7) logistic information management system report forms include the following: stock on hand, quantities used, losses and adjustments, (8) the health facility dispatch stock based on the following: First in First out (FIFO) and Last in Last out (LIFO), (9) physical count is made at regular intervals (at least once a month) and regularly in the health facility, and (10) there is monitoring of stock levels, stock quantities and safety stocks. Expiry drugs management was found to be excellent in the central medical stores as indicated in Figure 2.

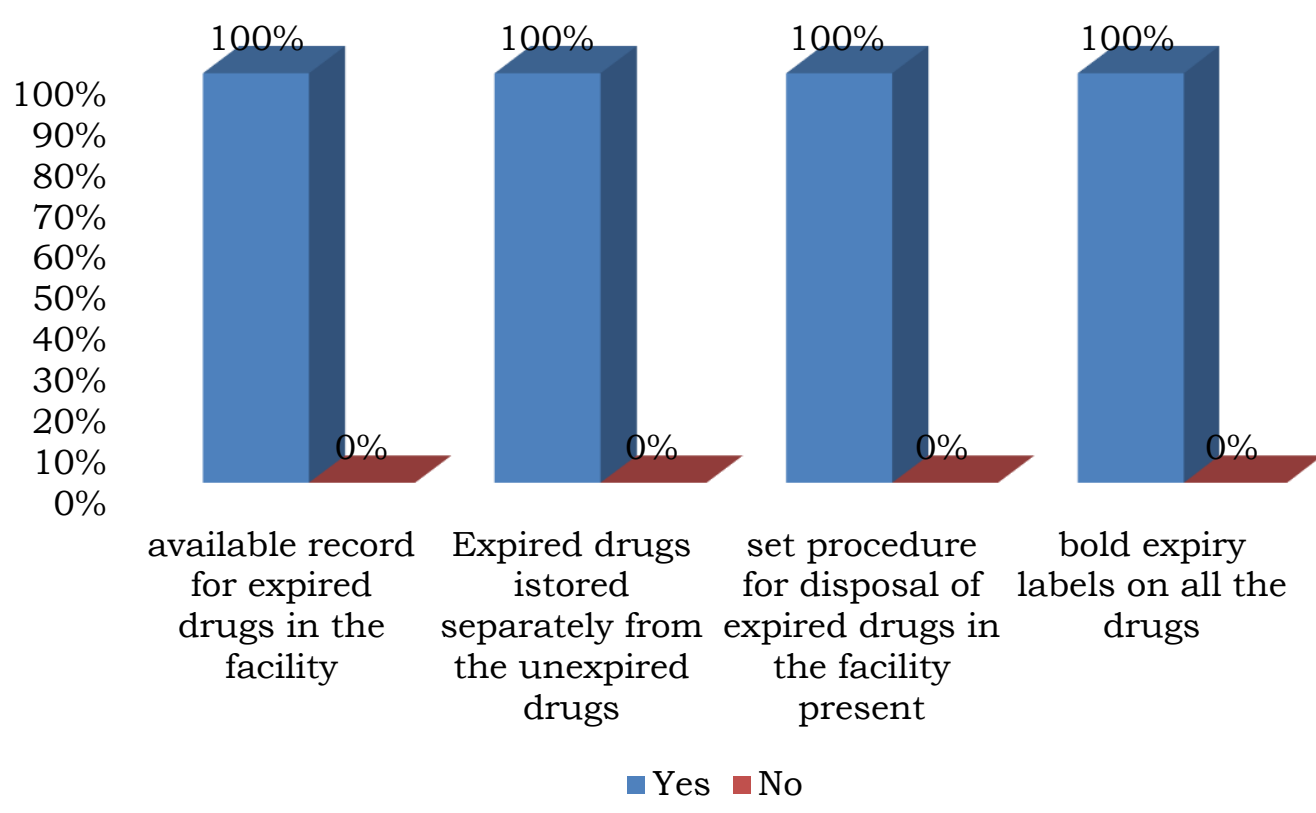

Figure 2. Results showing good Expiry drugs management practices in the Central Medical stores and Jubek State Pharmaceutical Department.

\section{Storeroom management conditions of the 8 PHCUs assessed}

The researcher assessed 8 Primary Health Care Units (PHCUs') in which 8 store keepers were assessed using selfassessed questionnaire. Findings showed that most of the PHCUs had poor storeroom conditions as compared to the hospitals and Medical stores assessed. For instance, the storage equipment was not adequate, and narcotic and psychotropic substances were not stocked in separate double locked storage space as per the ABCS of medical storage. However, the inventory and storeroom management practices were overall found to be good in the PHCUs. For example, the pharmacists were responsible for stocking and storing drugs and they recorded every drugs requisition by other departments properly. Figure 3 summarize these results. 


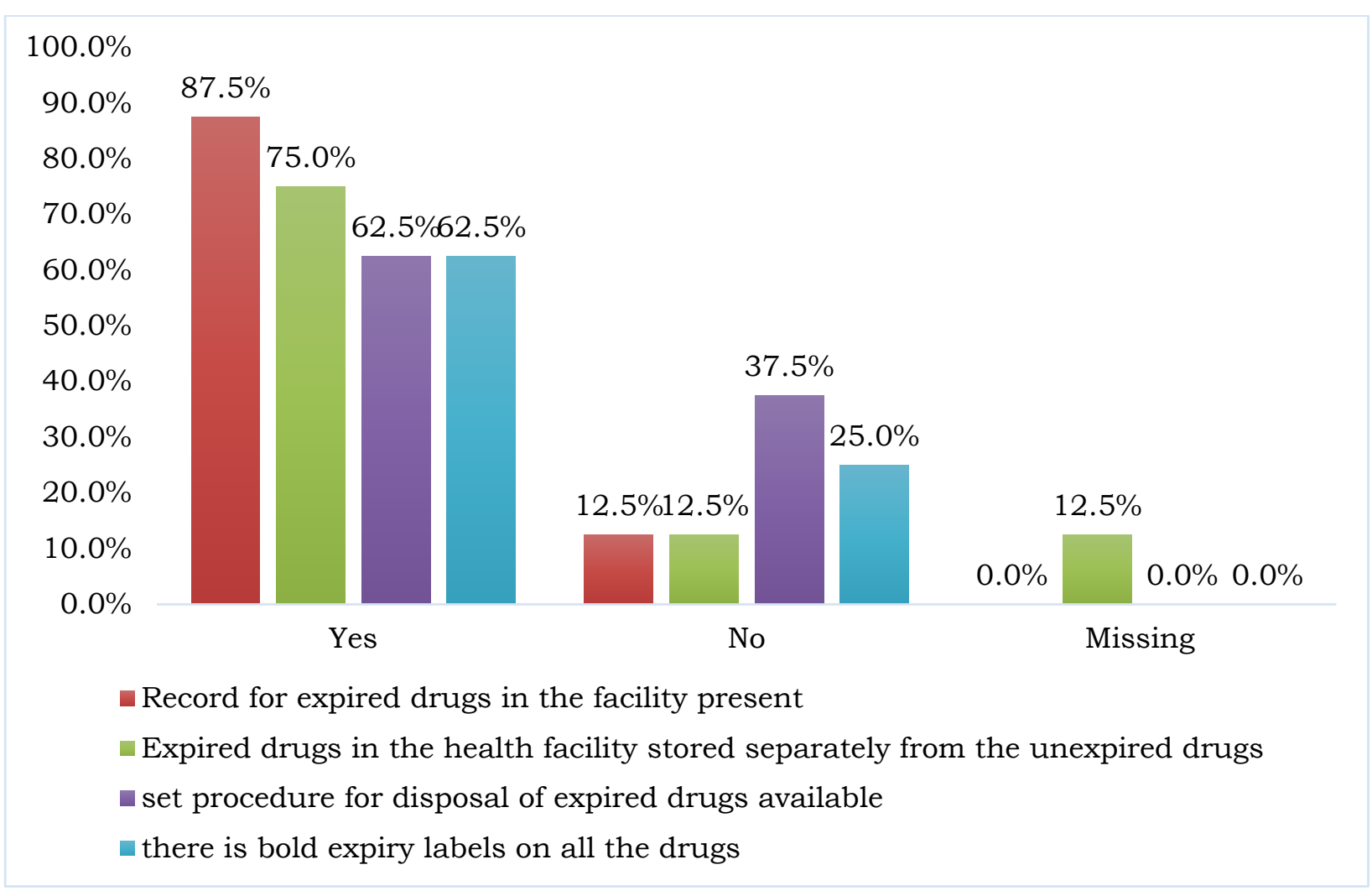

\section{Figure 3. Expiry management practices at the PHCU's assessed}

\section{Qualitative data}

\section{Knowledge of the health workers working in the store and inventory management}

The knowledge of the health workers on store and inventory management in the hospitals assessed was good most especially in their role of receiving the medicines and checking the stock card, monitoring stock level regularly (weekly and monthly). However, most of the stores do not have enough qualified staff. In the Medical stores assessed as summarized in Table 1, there was poor practice of storekeepers with regards to store and inventory management. In the PHCUs, the store keepers have exhibited good knowledge in store and inventory management as indicated in Table 2.

Table 1. Knowledge of store keepers on store and inventory management at the Central Medical store.

\begin{tabular}{|l|l|l|}
\hline \multicolumn{2}{|l|}{} & Remark \\
\hline $\begin{array}{l}\text { Can you please tell me about your role as } \\
\text { the pharmacist/ store keeper in ensuring } \\
\text { the availability of medicines at store? } \\
\begin{array}{l}\text { How often do you monitor or review } \\
\text { products stock levels at the store? }\end{array}\end{array}$ & Every month & Good \\
\hline How is stock level calculated & $\begin{array}{l}\text { we don't calculate, We are } \\
\text { using push system }\end{array}$ & Poor \\
\hline
\end{tabular}




\begin{tabular}{|l|l|l|}
\hline $\begin{array}{l}\text { Do you think there are enough people } \\
\text { involved in the management of medicine } \\
\text { stock? If yes, or no, please explain? }\end{array}$ & $\begin{array}{l}\text { We have enough staff but } \\
\text { not qualified. That is why } \\
\text { am doing the work myself }\end{array}$ & Poor \\
\hline $\begin{array}{l}\text { Are there Standard Operating Procedures } \\
\text { for Storage (SOP) in the store? Verify by } \\
\text { asking for a copy of the guidelines. }\end{array}$ & we don't have & Poor \\
\hline
\end{tabular}

Table 2. Knowledge of store keepers on store and inventory management at the PHCUs'

\begin{tabular}{|c|c|c|}
\hline & & Remark \\
\hline $\begin{array}{l}\text { Can you please tell me about } \\
\text { your role as the pharmacist/ } \\
\text { store keeper in ensuring the } \\
\text { availability of medicines at } \\
\text { store? } \\
\text { How often do you monitor or } \\
\text { review products stock levels at } \\
\text { the store? }\end{array}$ & $\begin{array}{l}\text { First we request the drug and add } \\
\text { buffer stock and also you need to } \\
\text { request in advance and we are } \\
\text { requesting according to our } \\
\text { consumption } \\
\text { Twice per day, morning when we arrive } \\
\text { and evening. }\end{array}$ & Good \\
\hline How is stock level calculated & $\begin{array}{l}\text { We calculate the amount that we } \\
\text { issue and how many remain then you } \\
\text { can out with } \\
\text { sum the calculation }\end{array}$ & Good \\
\hline $\begin{array}{l}\text { Do you think there are enough } \\
\text { people involved in the } \\
\text { management of medicine stock? } \\
\text { If yes, or no, please explain? }\end{array}$ & We have enough staff & Good \\
\hline $\begin{array}{l}\text { Are there Standard Operating } \\
\text { Procedures for Storage (SOP) in } \\
\text { the store? Verify by asking for a } \\
\text { copy of the guidelines. }\end{array}$ & we don't have & Poor \\
\hline
\end{tabular}

\section{Observation results}

Observation results showed that storage conditions and inventory management in the health facilities of Juba were good and similar to the questionnaire results. Eleven out of the 20 items observed scored $100 \%$ and 7 out of the 20 items scored $50 \%$ in the assessment made in the hospitals. For instance, In the hospitals, it was observed that supplies were arranged in alphabetical order, supplies were stored in sequence in which they came in the stores (FIFO), expired and damaged medicines were quarantined and separated from items in the storage area as per the standard guidelines for medical storage. In the Medical stores, $12 / 20$ of the items observed scored $100 \%$ in the assessment and 5/20 scored 50\%. As observed, medicines that easily react to the temperature were stored in a refrigerator. First in First out and Last in Last out was used in dispatch of medicines. Expired and damaged medicines were quarantined and separated from items in the storage area. In the PHCUs, most of the items 
observed $(7 / 20)$ scored $62 \%$ in the assessment. Similarly, in the PHCUs, it was observed that, sensitive items were kept in a refrigerator, supplies with an expiry date were stored according to First Expiry First out (FEFO). Expired and deteriorated medicines were quarantined and separated from items in the storage area. Store ceiling condition was poor in $50 \%$ of the PHCs.

\section{Discussion}

The quantitative results (from questionnaire) and results from observation indicated that generally the health facilities assessed had good store room management. These results coincide with a report from Federal Ministry of Health, Nigeria [9] which reported that health centers are usually run with a good store condition, with good infrastructure regarding storage, ventilation and security. However, average storeroom practices were also observed, including availability of expiry drugs in $50 \%$ of the hospitals. There was inadequate storage equipment in the hospitals assessed. Poor practices were found in maintenance of minimum stock level of drugs in the store that was not being done and poor monitoring of stock levels, stock quantities and safety stock of medicines. Procedures for disposal of expired drugs in the hospitals was found to be poor. This implies that Ministry of health South Sudan should provide enough storage equipment such as cold chain, refrigerators in the health facilities to aid in proper medicines storage and also conduct regular supervision of health facilities should be made by the inspectors of ministry of health to ensure that stores and health facilities respect and adhere to set guidelines.
In the medical stores assessed there was excellent storeroom and inventory management practices. However, this slightly differs from the assessment made using observation in which products arrangement in alphabetical order was average. According to Schopperle,[5] medicines generally need to be stored in warehouses under appropriate conditions of security, temperature and storage area.

Unlike in the hospitals and medical stores where most of the inventory assessed met the required standards, in the PHCUs, the store room assessment found poor condition. Store rooms were not having enough space, there was inadequate storage equipment's, windows were not well secured with curtains and grills, store ceiling were not in good condition which is similar from the observation assessment made in the PHCU by the researcher. This differed from the study by Monica et al. [10] In India which found that the pharmaceutical stock management in all the primary health centers were on a comparable stand whereby, stock ledgers were preserved to record all the details of every product of varying batch numbers supplied to the health facilities or store. Preservation of ledger records represented a perpetual inventory system, as it traced and tracked the quantity of stock in hand.

However, despite this, the inventory management system in the PHCUs was good. This is in line with the recommendation of Yadav et al.,[11] that for an efficient use of Logistical Management Information Systems, it is necessary that different medical programs standardize and harmonize their reporting requirements to decrease complexity. A record for expired drugs in 
the facility existed, separate storage of unexpired drugs from expired drugs were found proper in the PHCUs assessed which is similar to the assessment made by the researcher in which expired and damaged medicines are quarantined and separated from items in the storage area. Availability of expiry drugs labels also scored well. Procedures for disposal of expired drugs in the hospitals was found to be also good.

In the hospitals assessed, majority of the store keepers knew their roles in the stores as to monitor flow of medicines and to receive medicines and check the stock card. However, there were not enough qualified staff in the hospitals and there are no standard operating procedures in the hospitals stores. This backs up the report of South Sudan Health Sector Development Plan 20052016 that estimated that just $10 \%$ of the staffing norms are filled by appropriately trained health workers. This implies that a standard operating procedure should be availed by the ministry of health to all the health facilities in South Sudan and government should ensure that all health workers adhere to it so that proper inventory management practices are followed. Also, Health facilities should request for training on inventory control from the ministry of health.

\section{Conclusion}

In conclusion, store and inventory management practices and knowledge of the respondents varied in the different health facilities. Generally, hospitals and Central medical stores exhibited good practices in inventory and storeroom management practices than the PHCUs that exhibited poor and average practices. In the 8 PHCUs' assessed in which 8 store keepers were assessed using self-assessed questionnaire, findings showed that most of the PHCUs have poor storeroom conditions as compared to the hospitals and Medical stores assessed. However, the inventory and storeroom management practices were found to be good in the PHCUs as well. This therefore implies that Ministry of Health should add more equipment and improve storage conditions most especially the cold chain in the PHCUs.

\section{Competing interests}

The authors declare that there are no conflicts of interest.

\section{Acknowledgement}

The authors of this paper gratefully acknowledge the funding of the Masters of Health Supply Chain Management by the German Federal Ministry for Economic Cooperation and Development (BMZ) through KfW Development Bank and the East African Community Regional Center of Excellence for Vaccines, Immunization, and Health Supply Chain Management. In addition, this research would not have been possible without the assistance of the College of Medicine and Health Sciences, University of Rwanda.

\section{Authors' contributions}

AJM conceived the study, collected the data, and drafted the manuscript. KC and $\mathrm{MM}$ revised the data analysis, and critically reviewed the manuscript. All authors approved the final version of the manuscript.

This article is published open access under the Creative Commons Attribution-Non-Commercial No Derivatives (CC BYNC-ND4.0). People can copy and redistribute the article only for noncommercial purposes and as long as they give 
appropriate credit to the authors. They cannot distribute any modified material obtained by remixing, transforming or building upon this article.

See

https://creativecommons.org/licenses/by-ncnd/4.0/

\section{Reference}

1. World Health Organization. Regional Workshop On Improving ProcureMent \& Supply Management Systems in The African Region. World Health organization - Regional Office for Africa. 2018.

2. Awle IA. Relationship between effective drug inventory control management and stock-outs in Kenya's public hospitals: A case study of Kenyatta National hospital and defense forces memorial hospital (Masters Thesis). Strathmore University. 2016.

3. USAID: Deliver Project. The Logistics Handbook. A practical guide for the supply chain management of health commodities. Second ed. Arlington, USA: USAID, 2011.

4. Carvalho S. 2002 Annual Review of Development Effectiveness: Achieving Development Outcomes The Millennium Challenge. Annual Review of Development Effectiveness. Washington, DC: World Bank. 2003.

5. Schopperle A. Analysis of challenges of medical supply chains in SubSaharan Africa regarding inventory management and transport and distribution. (Project Thesis), University of Westminster. 2013.
6. Shafaat K, Hussain A, Kumar B, ul Hasan R, Praabhat P, Yadav VK. An overview: Storage of pharmaceutical products. World journal of pharmacy and pharmaceutical sciences, 2013; 2(5):2499-2515.

7. Ministry of Health, South Sudan. Health sector Development Plan 2012-2016.

8. Ministry of Environment and Physical Development, South Sudan. Republic of South Sudan's National Adaptation Programme of Actions (NAPA) to Climate Change. 2007.

9. World Health Organization. In-depth Assessment of Procurement and Supply Management Systems for Medical Products. Federal Ministry of Health, Nigeria. 2010.

10. Kokilam MB, Joshi HG, Kamath VG. Assessment of Pharmaceutical Store and Inventory Management in Rural Public Health Facilities-A study with reference to Udupi District, Karnataka. Pharmaceutical Methods. 2015; 6(2): 53-9.

11. Yadav $\mathrm{P}$, Tata $\mathrm{H}$, Babaley $\mathrm{M}$. The world's medicines situation 2011: storage and supply chain management. Geneva: WHO Press; 2011. 